\title{
Analisis Pengaruh Rasio Keuangan dan Good Corporate Governance Terhadap Income Smoothing Perbankan Syariah Di Indonesia (Studi Kasus Pada Bank Umum Syariah Periode 2012 - 2016)
}

\author{
Indar Fauziah Ulfah \\ indar@unis.ac.id \\ Program Studi Manajemen \\ Fakultas Ekonomi \\ Universitas Islam Syekh Yusuf Tangerang
}

Tujuan dari penelitian ini adalah untuk menguji apakah bank syariah di Indonesia melakukan manajemen laba dengan perataan laba. Variabel dependen yang digunakan dalam penelitian ini adalah praktik perataan laba (Income Smoothing), variabel independen yang digunakan dalam penelitian ini adalah rasio non performing financing (NPF), net profit margin (NPM), return on asset (ROA), financing to deposit ratio (FDR), dan Good corporate governance (GCG).

Obyek yang diteliti dalam penelitian ini adalah Bank Umum Syariah yang terdaftar di otoritas jasa keuangan (OJK) tahun 2014-2016. Sampel dipilih dengan menggunakan metode purposive sampling dan diperoleh 11 bank syariah menjadi sampel. Koefisien/indeks Eckel digunakan sebagai alat untuk mengidentifikasi praktik perataan laba. Selanjutnya dilakukan statistik deskriptif dan analisis regresi logistik untuk menguji setiap hipotesis.

Hasil penelitian menunjukkan bahwa bank syariah melakukan manajemen laba dengan praktek perataan laba. Selanjutnya, tiga variabel independen secara signifikan (NPM, ROA, GCG) positif dan negatif mempengaruhi variabel dependen, dan dua Variabel independen tidak signifikan (NPF,FDR). Sementara secara simultan kelima independen variabel berpengaruh signifikan terhadap variabel dependen.

Kata Kunci: Manajemen Laba, Perataan Laba, Bank Umum Syariah, Indeks Eckel, Akuntansi syariah 


\section{A. PENDAHULUAN}

Bank Indonesia (BI) mulai mengawasi perhitungan manajemen dua risiko tambahan di bank syariah, yakni risiko investasi (Equity of investment risk) dan risiko imbal hasil (rate of return risk). Meski belum diperhitungkan dalam penilaian risiko (risk profile), bank syariah diminta menghitung berapa modal untuk pengelolaan kedua risiko tersebut. Kedua risiko itu telah diterbitkan dalam Peraturan Bank Indonesia (PBI) Nomor 13/23/PBI/2011 tentang Penerapan Manajemen Risiko bagi Bank Umum Syariah dan Unit Usaha Syariah.

Dalam mengurangi tingkat resiko investasi dan menjaga tingkat bagi hasil agar tetap di level yang aman, IFSB membuat guideline for income smoothing in sharia bank, yaitu teknik perataan laba pada bank syariah yang menjaga agar tingkat fluktuatif laba tidak terlalu tinggi, sehingga mampu memberikan tingkat imbal hasil yang kompetitif dalam industri perbankan (IFSB, 2010). Income smoothing merupakan bagian dari earning management.

Dalam income smoothing ini volatilitas laba yang tinggi pada bank syariah dapat diminimalisir dengan pengurangan dan pencadangan bagi hasil untuk mengantisipasi adanya kerugian di masa mendatang, IFSB memberlakukan metode PER (Profit Equalization Reserve) dan IRR (Investment Risk Reserve), dalam bahasa ekonomisnya adalah bahwa implementasi dari PER dan IRR ditujukan untuk membantu mengelola tingkat Displaced Commercial Risk (DCR) yang didefinisikan sebagai sebuah resiko yang muncul ketika Bank Syariah berada dalam tekanan untuk memberikan hasil (return) yang lebih tinggi kepada Investor/ deposannya melebihi yang seharusnya diberikan berdasarkan kontrak investasi sebelumnya.

Indonesia melalui Fatwa DSN NO: 87/DSN-MUIIXII/2012 memperbolehkan adanya income smoothing tersebut hanya dengan metode PER (Profit Equalization Reserve), Ketersediaan informasi yang dipublikasikan oleh Bank Syariah dalam hal praktek PER ataupun IRR sangat terbatas. Dalam sebuah analisa atas pengungkapan praktek tersebut (berdasarkan laporan tahunan 2009-2014), 
hanya sekitar 30\% saja dari bank-bank yang disurvei, yang mengungkapkan jumlah PER dalam neraca mereka.

Penelitian ini juga menganalisis peranan Corporate Governance (CG) dalam memoderasi tingkat manajemen laba. Jiang et al. (2008) dan Laela (2012) menyatakan jika mekanisme CG yang semakin baik dapat meningkatkan kemampuan prediktabilitas laba. Hal ini disebabkan peningkatan transparansi dalam pelaporan keuangan yang meningkatkan akurasi pengambilan keputusan dari pengguna laporan keuangan. Mekanisme CG yang semakin baik juga terbukti memperlemah manajemen laba (Laela, 2012; Oktaviyanti, 2013).Mekanisme CG dalam penelitian ini diukur menggunakan skor self-assessment pelaksanaan CG oleh bank umum. Skor ini diharapkan dapat merefleksikan pelaksanaan CG secara komprehensif di sektor perbankan. Hal ini dimungkinkan karena menurut SE BI No.15/15/DPNP tahun 2013, dalam skor ini terdapat penilaian komprehensif atas governance structure, governance process, dan governance outcome di sektor perbankan.

Berdasarkan beberapa kasus skandal pelaporan keuangan seperti insider trading pada saham PT Bank Central Asia tahun 2001 maupun kasus laporan keuangan ganda PT Bank Lippo pada tahun 2002 yang diterbitkan oleh pihak manajemen perusahaan yang melibatkan pelaporan keuangan (financial reporting) yang berawal dari terdeteksi adanya manipulasi (Boediono, 2005). Penyalahgunaan informasi keuangan ini banyak merugikan pihak-pihak yang berkepentingan terutama para investor yang akan menanamkan modalnya, fenomena ini telah menimbulkan pertanyaan bagaimana efektivitas penerapan good corporate governance (GCG) dalam sebuah perusahaan untuk meminimalkan manjemen laba.

Diharapkan penelitian ini mampu melihat sejauh mana rasio keuangan yang diproksikan dengan NPF, NPM, ROA dan FDR Bank Umum Syariah serta Good Corporate Governance yang diproksikan melalui self score assessment sebagai perisai dalam mengawasi sharia compliance mampu meminimalisir praktik income smoothing tersebut. Maka penulis tertarik untuk mengangkat judul Analisis Pengaruh Rasio 
Keuangan dan Good Corporate Governance terhadap Income Smoothing Perbankan Syariah di Indonesia (Studi Kasus Bank Umum Syariah periode 20122016)

\section{B. PENELITIAN TERDAHULU}

Penelitian terdahulu yang meneliti adanya pengaruh rasio CAMEL terhadap praktik manajemen laba yaitu penelitian Zahara dan Siregar (2009) dengan menggunakan proksi rasio CAR, RORA, ROA, NPM, dan LDR hasil penelitian ini tidak ditemukannya praktik manajemen laba pada bank syariah, hanya rasio NPM yang berpengaruh positif dan signifikan terhadap perataan laba.

Penelitian Senja (2011) dengan menggunakan proksi rasio CAR, NPL, ROA, NIM, dan LDR pada perbankan go public menemukan secara simultan mempunyai pengaruh signifikan terhadap perataan laba, namun secara parsial hanya rasio NIM yang berpengaruh signifikan terhadap manajemen Iaba Penelitian Luh Gede Kusuma Dewi, I Wayan Suartana, I Putra Astika (2011) Rasio CAR, ROA, dan NPM berpengaruh negatif tidak signifikan terhadap manajemen laba di BPR Provinsi Bali, rasio RORA dan LDR berpengaruh signifikan pada manajemen laba di BPR Provinsi Bali.

Penelitian Fentje Salhuteru \& Fransina Wattimena (2015) menemukan Pada bank pemerintah, rasio CAR, dan MR berpengaruh negatif pada manajemen laba, rasio RORA, ROA dan LDR berpengaruh positif tetapi tidak signifikan, rasio NPM berpengaruh positif dan signifikan terhadap manajemen laba. Pada bank swasta, rasio CAR, LDR berpengaruh negatif terhadap manajemen laba, rasio RORA, dan MR berpengaruh positif tetapi tidak signifikan, rasio ROA dan NPM berpengaruh positif dan signifikan terhadap manajemen laba. 


\section{METODOLOGI PENELITIAN}

Populasi dalam penelitian ini adalah seluruh bank syariah di indonesia baik BUS, UUS ataupun BPRS, sedangkan sampel yang digunakan yaitu bank umum syariah yang memiliki laporan keuangan tahunan lengkap periode 2012 - 2016 yang berjumlah 11 bank umum syariah. Metode pengambilan sampel menggunakan purposive sampling method. Jenis penelitian ini didesain dengan metode kuantitatif, dengan menggunakan data sekunder. Data sekunder didapatkan dari data yang sudah dipublikasikan di situs resmi masing-masing bank umum syariah. Dalam penelitian ini terdapat dua macam variabel penelitian yaitu variabel independen atau variabel bebas $(X)$ dan variabel dependen atau variabel terikat $(Y)$. Variabel independen dalam penelitian ini adalah rasio keuangan yang diproksikan dengan NPF, NPM, ROA dan FDR serta Good Corporate governance dengan proksi menggunakan self score assessment. Sedangkan variabel dependen dalam penelitian ini adalah Praktik Perataan Laba (Income smoothing), dengan deteksi awal menggunakan indeks eckel dan dilanjutkan dengan teknik analisis regresi logistik dengan menggunakan software eviews 10.

Untuk memperjelas variabel yang ada dalam penelitian ini maka dapat diuraikan definisi dari variabel-variabel tersebut yaitu:

\section{1) Variabel Dependen}

Variabel dependen dalam penelitian ini adalah praktik perataan laba (income smoothing) yang diuji dengan menggunakan rumus Indeks Eckel (1981: 28-40) menggunakan coefficient variation (CV) variabel net income (total laba) dan variabel sales (total pendapatan operasional).

\section{2) Variabel Independen}

a. Non Performing Financing (X1)

Non Performing Financing menunjukan kemampuan manajemen bank dalam mengelola pembiayaan bermasalah yang diberikan oleh bank. Sehingga semakin tinggi rasio ini maka akan semakin semakin buruk kualitas 
pembiayaan bank yang menyebabkan jumlah pembiayaan bermasalah semakin besar maka kemungkinan suatu bank dalam kondisi bermasalah semakin besar.

b. Net Profit Margin (X2)

Net Profit Margin (NPM) adalah rasio profitabilitas yang digunakan untuk menghitung sejauh mana kemampuan perusahaan menghasilkan laba bersih setelah pajak pada tingkat penjualan tertentu. NPM dapat diinterprestasikan sebagai tingkat efisiensi perusahaan, yaitu kemampuan perusahaan dalam menekan biaya-biaya yang akan dikeluarkan perusahaan pada periode tertentu.

c. Return On Asset (X3)

Menurut Dendawijaya (2003: 120) rasio ini digunakan untuk mengukur kemampuan manajemen dalam memperoleh keuntungan (laba) secara keseluruhan. Semakin besar ROA, semakin besar pula tingkat keuntungan yang dicapai oleh perusahaan tersebut dan semakin baik pula posisi perusahaan tersebut dari segi penggunaan asset.

d. Financing to Deposit Ratio (X4)

FDR adalah perbandingan antara pembiayaan yang diberikan oleh bank dengan dana pihak ketiga yang berhasil dikerahkan oleh bank (Muhammad, 2005). Nilai FDR yang diperkenankan oleh Bank Indonesia adalah pada kisaran $78 \%$ hingga $100 \%$.

e. Self Assessment GCG (X5)

Skor hasil self assessment pelaksanaan CG diharapkan mampu merefleksikan pelaksanaan CG perbankan secara komprehensif. Hal ini dimungkinkan karema semua unsur penilaian good corporate governance sudah termasuk dalam komponen self assessment.

Diasumsikan bahwa semakin baik peringkat self assessment pelaksanaan CG perbankan syariah, maka semakin rendah perataan laba 
yang dilakukan, atau memininalisir kecenderungan perbankan syariah untuk melakukan perataan laba.

Metode analisis data menggunakan statistik deskriptif dan analisis Regresi Logistik (logistic regression). Uji Regresi Logistik dilakukan karena variabel dependen dalam penelitian ini adalah variabel dummy. Tujuan dilakukan regresi logistik ini adalah untuk pembuatan sebuah model regresi untuk memprediksi besar variabel dependen yang berupa sebuah variabel binary menggunakan data variabel independen yang sudah diketahui besarnya. (Santoso, 2015)

Regresi logistik tidak memiliki asumsi normalitas dan heteroskedastisitas atas variabel bebas yang digunakan dalam model sehingga tidak diperlukan uji asumsi klasik walaupun variabel independen berjumlah lebih dari satu.

Untuk menguji faktor- faktor apa saja yang mempengaruhi praktik perataan laba (income smoothing) digunakan software Microsoft Excel 7 dan EViews 10 untuk pengolahan data penelitian. Secara matematis model penelitian yang digunakan sebagai berikut:

$$
\ln \left[\frac{P_{i}}{1-P_{i}}\right]=\beta 0+\beta 1 \mathrm{NPF}+\beta 2 \mathrm{NPM}+\beta 3 \mathrm{ROA}+\beta 4 \mathrm{FDR}+\beta 5 \mathrm{GCG}
$$

\section{ANALISIS DAN PEMBAHASAN}

1. Uji Koefisien Determinasi $\left(\mathrm{R}^{2} \mathrm{McFadden}\right)$

Dalam regresi logistik, tidak dapat menggunakan nilai koefisien $R^{2}$ konvensional untuk mengukur kebaikan garis regresi. Sebagai penggantinya, digunakan koefisien determinasi yang dkembangkan oleh McFadden. 


\section{Tabel 4.11}

McFadden

Uji Koefisien Determinasi ( $\mathbf{R}^{2}$ McFadden)

squared R-

S.D. dependent var 0.401386

Mean dependent

0.340681 var

0.805556

Akaike info criterion0.982899

S.E. of regression 0.355856

Sum squared

resid

3.799011

Schwarz criterion
Hannan-Quinn

criter.

1.246819

Log likelihood -11.69218

criter.

1.075014

Deviance

23.38436

Restr. Deviance

35.46746

Restr.

$\log$

likelihood

Avg.

LR statistic

12.08310 likelihood

$-17.73373$

$\log$

Prob(LR statistic)

0.033667

$\begin{array}{llll}\text { Obs with Dep }=0 & 11 & \text { Total obs } & 55 \\ \text { Obs with Dep }=1 & 44\end{array} \quad$

Sumber: data diolah dengan menggunakan EViews 10.0 (2017)

Dalam penelitian ini diketahui bahwa, nilai $R^{2}$ McFadden dari hasil estimasi sebesar 0.340681. Hal ini berarti bahwa variabel bebas (NPF, NPM, ROA, FDR, GCG) dalam model mampu menerangkan perubahan probabilitas perataan laba (income smoothing) sebesar 34,07\% dan selebihnya 65,93\% dijelaskan oleh variabel lain diluar model.

Menurut Gujarati dan Porter (2012:199), penting untuk diketahui bahwa dalam model regresi bervariabel dependen yang biner, goodness of fit adalah nomor dua terpenting. Yang paling penting adalah nilai koefisien variabel independen bersifat positif atau negatif, dan signifikansi nilainya secara statistik dan/atau praktik. 


\section{Uji Likelihood Ratio (Uji LR)}

Uji statistik likelihood ratio (LR) untuk menguji apakah semua variabel penjelas secara bersama-sama mempengaruhi variabel dependen. Uji statistik likelihood ratio (LR) sebagaimana uji $\mathrm{F}$ pada regresi metode OLS. Uji LR dapat dilakukan dengan membandingkan nilai chi-square hitung dengan chi-square tabel, jika nilai chi-square hitung > nilai chi-square tabel, maka menolak Ho yang berarti semua variabel penjelas secara bersama-sama mempengaruhi variabel dependen, sedangkan jika sebaliknya, maka menerima Ho yang berarti semua variabel penjelas secara bersama-sama tidak mempengaruhi variabel dependen.

Berdasarkan hasil estimasi, diperoleh nilai LR statistik atau chi-square hitung adalah 12,083, sedangkan nilai chi-square tabel $\mathrm{df} 4, \mathrm{a}=0,05$ diperoleh sebesar 11,07 . Nilai LR statistik atau chi-square hitung $(12,083)>$ nilai chi-square tabel $(11,07)$.

Selain itu, dapat melihat Uji LR dengan membandingkan Prob (LR statistics) pada a, nila Prob (LR statistics) 0,033667 < 0.05, maka keputusannya adalah menolak Ho dan menerima Ha yang berarti semua variabel independen secara bersamasama mempengaruhi variabel dependen.

\section{Uji Statistik Z}

Uji Z dilakukan untuk mengetahui apakah variabel independen secara individual mempengaruhi variabel dependen. Uji $\mathrm{Z}$ dapat dilakukan dengan membandingkan nilai probabilitas terhadap a, jika nilai probabilitas < a, maka Ho ditolak yang berarti bahwa variabel independen mempengaruhi variabel dependen, sedangkan jika nilai probabilitas > a, maka Ho diterima yang berarti bahwa variabel independen tidak mempengaruhi variabel dependen. 


\section{Tabel 4.13}

\section{Uji Statistik Z}

\begin{tabular}{crrr}
$\begin{array}{c}\text { Variabe } \\
1\end{array}$ & $\begin{array}{r}\text { Coefficie } \\
\text { nt }\end{array}$ & $\begin{array}{r}\text { z- } \\
\text { Statistic }\end{array}$ & Prob. \\
\hline \hline C & 1.998315 & 0.633315 & 0.0035 \\
NPF & 3.314070 & 1.105904 & 0.2688 \\
NPM & 2.490500 & 0.990672 & 0.0018 \\
ROA & 3.443333 & 0.797114 & 0.0459 \\
FDR & 1.285860 & 0.387614 & 0.6983 \\
& & - & \\
GCG & -2.017767 & 1.960533 & 0.0499
\end{tabular}

diolah dengan menggunakan EViews 10.0 (2017)

Sumber: data

Berikut ini adalah hasil Uji Z dari masing-masing variabel independen terhadap variabel dependen

\section{a. Variabel NPF}

Berdasarkan hasil output dapat dilihat bahwa nilai probabilitas variabel independen NPF sebesar 0.2688 . Bila dibandingkan dengan $a=5 \%$, maka nilai probabilitas $(0.2688)>$ nilai a $(0.05)$, sehingga dapat diambil keputusan untuk menolak Ha dan menerima Ho. Hal ini dapat disimpulkan bahwa variabel rasio keuangan yang diproksikan dengan rasio non performance financing tidak berpengaruh signifikan positif terhadap perataan laba (income smoothing).

\section{b. Variabel NPM}

Berdasarkan hasil output dapat dilihat bahwa variabel rasio keuangan yang diproksikan dengan net profit margin memiliki probabiltas sebesar 0.0018. Bila dibandingkan dengan $a=5 \%$, maka nilai probabilitas $(0.0018)<$ nilai $a(0.05)$, sehingga dapat diambil keputusan untuk menolak Ho dan menerima Ha. Hal ini dapat disimpulkan bahwa variabel NPM perusahaan berpengaruh signifikan positif terhadap perataan laba (income smoothing). 


\section{c. Variabel ROA}

Berdasarkan hasil output dapat dilihat bahwa nilai probabilitas variabel independen profitabilitas yang diproksikan dengan return on assets sebesar 0.0459. Bila dibandingkan dengan $a=5 \%$, maka nilai $\operatorname{ROA}(0.0459)<$ nilai $a$ (0.05), sehingga dapat diambil keputusan untuk menerima Ha dan menolak Ho. Hal ini dapat disimpulkan bahwa variable rasio keuangan yang diproksikan dengan return on asset berpengaruh positif signifikan terhadap perataan laba (income smoothing).

\section{d. Variabel FDR}

Berdasarkan hasil output dapat dilihat bahwa variabel rasio keuangan yang diproksikan dengan financing to deposit ratio memiliki probabiltas sebesar 0.6983. Bila dibandingkan dengan $\alpha=5 \%$, maka nilai probabilitas $(0.6983)>$ nilai $\alpha$ (0.05), sehingga dapat diambil keputusan untuk menolak Ha dan menerima Ho. Hal ini dapat disimpulkan bahwa variabel FDR bank umum syariah tidak berpengaruh signifikan terhadap perataan laba (income smoothing).

e. Variabel GCG

Berdasarkan hasil output dapat dilihat bahwa variabel GCG yang diproksikan dengan self assessment score memiliki probabiltas sebesar 0.0499. Bila dibandingkan dengan $a=5 \%$, maka nilai probabilitas $(0.0499)<$ nilai a $(0.05)$, sehingga dapat diambil keputusan untuk menolak Ho dan menerima Ha. Hal ini dapat disimpulkan bahwa variabel GCG bank umum syariah berpengaruh signifikan negatif terhadap perataan laba (income smoothing).

E. Persamaan Analisis Regresi Logistik

Berikut hasil output dari alat analisis Eviews untuk regresi logistik dengan tabel hasil estimasi model logit 
Tabel 4.14

\section{Hasil Estimasi Model Logit}

Dependent Variable: IC_SM

Method: ML - Binary Probit (Newton-Raphson / Marquardt steps)

Date: 12/30/17 Time: 05:45

Sample: 20122016

Included observations: 55

Convergence achieved after 6 iterations

Coefficient covariance computed using observed Hessian

\begin{tabular}{crrrr}
\hline \hline \multicolumn{1}{c}{ Variable } & Coefficient & Std. Error & z-Statistic & Prob. \\
\hline C & 1.998315 & 3.155327 & 0.633315 & 0.0035 \\
NPF & 3.314070 & 2.996706 & 1.105904 & 0.2688 \\
NPM & 2.490500 & 2.513950 & 0.990672 & 0.0018 \\
ROA & 3.443333 & 4.319750 & 0.797114 & 0.0459 \\
FDR & 1.285860 & 3.317375 & 0.387614 & 0.6983 \\
GCG & -2.017767 & 1.029193 & -1.960533 & 0.0499 \\
\hline \hline McFadden R- & & & & \\
squared & 0.340681 & Mean dependent var & 0.805556 \\
S.D. dependent var & 0.401386 & S.E. of regression & 0.355856 \\
Akaike info criterion & 0.982899 & Sum squared resid & 3.799011 \\
Schwarz criterion & 1.246819 & Log likelihood & -11.69218 \\
Hannan-Quinn & & & & \\
criter. & 1.075014 & Deviance & 23.38436 \\
Restr. Deviance & 35.46746 & Restr. log likelihood & -17.73373 \\
LR statistic & 12.08310 & Avg. log likelihood & -0.324783 \\
Prob(LR statistic) & 0.033667 & & \\
\hline \hline
\end{tabular}

Obs with Dep $=0$

11 Total obs

55

Obs with Dep $=1$

44

Sumber: data diolah dengan menggunakan EViews 10.0 (2017)

Berdasarkan hasil output diatas, maka diperoleh persamaan model logit sebagai berikut :

$\ln \left[\frac{P_{i}^{n}}{1-P_{i}^{i}}\right]=1.998315+2.490500 \mathrm{NPM}+3,44333 \mathrm{ROA}-2.017767 \mathrm{GCG}$ 
Dari persamaan regresi di atas, untuk variabel yang mempengaruhi secara signifikan dapat dijelaskan bahwa:

1) Berdasarkan persamaan regresi di atas, diperoleh koefisien regresi untuk konstanta sebesar 1.998315. Hal ini mengindikasikan bahwa jika variabel independen sama dengan 0 , maka kemungkinan terjadinya praktik perataan laba meningkat sebesar $1.99 \%$.

2) Koefisien dari variabel rasio keuangan yang diproksikan dengan net profit margin (NPM) sebesar 2.490500 dan berpengaruh signifikan pada $a=5 \%$. Jika menghitung antilog dari 2,49, didapatkan hasil sebesar $\mathrm{e}^{2,49}=12,08$. Hal ini berarti jika persentase net profit margin (NPM) meningkat 1\%, maka kemungkinan meningkatnya tindakan perataan laba (income smoothing) sebesar $12,08 \%$ dengan asumsi variabel lainnya konstan.

3) Return on asset (ROA) sebesar positif 3.44333 dan berpengaruh signifikan pada $\alpha=5 \%$. Jika menghitung antilog dari 3,4 didapatkan hasil sebesar $\mathrm{e}^{3.44=}$ 31,25. Hal ini berarti jika persentase profitabilitas (ROA) meningkat 1\%, maka kemungkinan meningkatnya tindakan perataan laba (income smoothing) sebesar 31,25\% dengan asumsi variabel lainnya konstan.

4) Koefisien dari variabel GCG sebesar negatif 2.017767 dan berpengaruh signifikan pada $a=5 \%$. Jika menghitung antilog dari 0.71 , didapatkan hasil sebesar $\mathrm{e}^{2,02}=7,55 \mathrm{Hal}$ ini berarti jika skor self assessment GCG meningkat 1\%, maka kemungkinan menurunnya praktik perataan laba (income smoothing) sebesar 7,55\% dengan asumsi variabel lainnya konstan.

\section{KESIMPULAN DAN SARAN}

Berdasarkan hasil analisis regresi logistik dari pengaruh rasio keuangan yang diproksikan dengan Non Performance Financing (NPF), Net Profit Margin (NPM), Return on Asset (ROA), Financing to Deposit Ratio (FDR) dan Good Corporate Governance (GCG) yang diproksikan dengan Self 
Score Assessment terhadap praktik perataan laba Bank Umum Syariah (Income Smoothing) dapat diambil kesimpulan sebagai berikut:

1. Secara parsial Net Profit Margin (NPM) mempunyai pengaruh yang positif signifikan terhadap praktik perataan laba Bank Umum Syariah (Income Smoothing).

2. Secara parsial Return On Asset (ROA) mempunyai pengaruh yang positif signifikan terhadap praktik perataan laba Bank Umum Syariah (Income Smoothing

3. Secara parsial Good Corporate Governance (GCG) berpengaruh negatif signifikan terhadap praktik perataan laba Bank Umum Syariah (Income Smoothing).

4. Secara parsial Non Performance Financing (NPF) dan Financing to Deposit Ratio (FDR) berpengaruh positif namun tidak signifikan terhadap perataan laba Bank Umum Syariah (Income Smoothing).

5. Secara simultan Non Performance Financing (NPF), Net Profit Margin (NPM), Return on Asset (ROA), Financing to Deposit Ratio (FDR) dan Good Corporate Governance (GCG) yang diproksikan dengan Self Score Assessment terhadap praktik perataan laba Bank Umum Syariah (Income Smoothing) di Indonesia.

\section{IMPLIKASI}

Penelitian ini dapat memberikan tambahan pengetahuan bagi seluruh bank umum syariah tentang praktik perataan laba yang sudah sering dilakukan dan bagaimana agar mampu memaksimalkan potensi mencapai laba namun tetap berada pada tata kelola perusahaan yang baik, tidak melanggar sharia compliance dan mengedepankan aspek dan nilai syariah.

Dua isu penting yang menjadi ancaman sekaligus tantangan bagi perbankan syariah yaitu fintech dan disruption seharusnya dapat ditindak 
lanjuti dengan meningkatkan kualitas SDM terutama dalam bidang IT, sehingga perataan laba bukan lagi menjadi jalan dalam meningkatkan pangsa pasar perbankan syariah.

A. Saran

Untuk penyempurnaan penelitian ini dan pengembangan ilmu pengetahuan, penulis mengajukan sedikit saran mengenai bahasan yang terkait dalam penelitian ini:

1. Penelitian selanjutnya diharapkan memperluas sampel yang digunakan yakni bisa menggunakan seluruh bank syariah di Indonesia yakni Bank Umum Syariah, dan Unit Usaha Syariah atau juga bisa ditambahkan dengan BPRS Syariah.

2. Penelitian selanjutnya sebaiknya menggunakan proksi lain, misalnya saja untuk profitabilitas bisa diproksikan dengan return on equity, net income margin, net Operational margin.

3. Penelitian selanjutnya sebaiknya menggunakan rentang waktu yang lebih lama agar hasil perataan laba (income smoothing) lebih digambarkan secara akurat.

\section{DAFTAR PUSTAKA}

Assih,Prihat dan M.Gudono. 2000. “Hubungan Tindakan Perataan Laba dengan Reaksi Pasar atas Pengumuman Informasi Laba Perusahaan yang Terdaftar di Bursa Efek Jakarta". Jurnal Riset Akuntansi Indonesia, 3 (1). Januari, h: 35 53.

Atik,Asuman.2008. Detecting income-smoothing behaviors of Turkish listed companies through empirical test using discretionary accounting changes. Critical Perspectives on Accounting, Vol.20, p 591-613.

Bank Indonesia. 2008. Undang-Undang Nomor 21 tahun 2008 Tentang Perbankan Syariah. Jakarta

Belkaouli. (2000). Teori Akuntansi. Buku 1. Translator: Marwata, et.al. Jakarta: Salemba Empat.

Budiasih, I. (2009). Faktor-faktor yang mempengaruhi praktik perataan laba. Jurnal Akuntansi dan Bisnis, 4, 44-50. Retreived from ojs.unud. 
Budiasih, Igan.2009. Faktor-Faktor yang Mempengaruhi Praktik Perataan Laba.Media AUDI Jurnal Akuntansi dan Bisnis, Vol. 4. Januari, hal:1-14.

Cahyani, Nuvita Dwi .2012. Pengaruh Profiabilitas, Risiko Keuangan, Nilai Perusahaan, Struktur Kepemilikan, Ukuran Perusahaan dan Jenis industry Terhadap Praktek Perataan Laba Pada Perusahaan Yang Terdaftar di Bursa Efek Indonesia Periode Tahun 2006-2010. Juraksi.1(2). Februari 2012

Cornett M. M, J. Marcuss, Saunders dan Tehranian H. 2006. Earnings Management, Corporate Governance, and True Financial Performance. http://papers.ssrn.com/ Eisenhardt,

Eckel, N. (1981). The Income Smoothing Hypothesis Revisited. Abacus. 17 (1), 28-40.

Effendi, Muhammad Arief. 2009. The Power of Good Corporate Governance; Teori dan Implementasi. Jakarta : Salemba Empat

Elnahass, M., M. Izzeldin dan O. Abdelsalam. 2014. Loan loss provisions, Bank Valuations and Discretion: A Comparative Study Between Conventional and Islamic Banks. Journal of Economic Behaviour and Organization 103, S160S173.

Fatwa DSN NO: 87/DSN-MU/XII/2012 tentang Metode Perataan Penghasilan (Income Smoothing) Dana Pihak Ketiga

Ghozali, Imam. (2005) Aplikasi Analisis Multivariate Dengan Program SPSS, Edisi Ketiga, Badan Penerbit Universitas Diponegoro, Semarang

Ghozali, Imam. "Manajemen Risiko Perbankan". Semarang : BPUNDIP, 2007.

Healy, Paul M. and J.M. Wahlen. 1999. A Review of The Earnings Management Literature and Its Implications for Standard Setting. Accounting Horizons 13, Pp. 365-383.

Ismail, A.G.B., R.S. Shaharudin, dan A.R. Samudhram. 2006. “Do Malaysian Banks Manage Earnings Through PPAPs?". Journal of Financial Reporting and Accounting, Vol. 3, h. 41-47.

Jensen, M. C., and W.H. Meckling, 1976. Theory of the Firm: Managerial Behavior, Agency Costs and Ownership Structure. Journal of Financial Economics, Vol.3, No. 4, October.

Kasmir. 2011. Analisis Laporan Keuangan. Jakarta: Rajawali Pers

Kathleem. M. 1989. Agency Theory: An Assesment and Review. Academy of Management Review, 14, Pp. 57-74.

Kusumawati, Eny. Sari, Shinta Permata dan Trisnawati, Rina. (2013) "Pengaruh Asimetri Informasi Dan Mekanisme Corporate Governance Terhadap Praktik Earnings Management". Universitas Muhammadiyah Surakarta.

Laela, S. F. 2012. Kualitas Laba dan Corporate Governance: Benarkah Kualitas Laba Bank Syariah Lebih Rendah dari Bank Konvensional? Jurnal Akuntansi dan Keuangan Indonesia, 9 (1), 22-42

Oktaviyanti. 2013. Pengaruh Volatilitas Laba pada Manajemen Laba Perbankan dengan Moderasi Self Assesment Corporate Governance, Struktur Kepemilikan dan Kualitas Audit. Tesis, Universitas Indonesia. 
Padmantyo, Sri. (2010) “Analisis Manajemen Laba Pada Laporan Keuangan Perbankan Syariah". Universitas Muhammadiyah Surakarta. BENEFIT Jurnal Manajemen dan Bisnis Volume 14, Nomor 2, hal, 256-272

Peraturan Bank Indonesia. 2006. Nomor 11/33/PBI/2009 Tentang Pelaksanaan Good Corporate Governance Bagi Bank Umum Syariah Dan Unit Usaha Syariah.

Pernyataan Standar Akuntansi Keuangan (PSAK) No. 1 tentang Penyajian Laporan Keuangan. 